\title{
Optimization of nickel ions removal from aqueous solutions by chitosan-polyethylene oxide electrospun nanofibers
}

\author{
I. Lakhdhar, P. Mangin \& B. Chabot \\ Centre de recherche sur les matériaux lignocellulosiques, \\ Université du Québec à Trois-Rivières, Canada
}

\begin{abstract}
Chitosan-polyethylene oxide (Cs/PEO) electrospun nanofibers were prepared by electrospinning process in order to remove nickel ions from aqueous solutions by a chelation mechanism. Response surface methodology (RSM) was used to optimize adsorption efficiency of nickel ions on Cs/PEO nanofibers. The combined effects of adsorption operating parameters, namely, the adsorbent dose, initial nickel ions concentration, temperature, and $\mathrm{NaCl}$ concentration, on adsorption efficiency were investigated using a central composite face-centered (CCF) design. Results showed that an optimal adsorption capacity of $64.4 \%$ was obtained under the following conditions: $75 \mathrm{mg}$ of adsorbent dose, initial nickel concentration of $100 \mathrm{ppm}$, a temperature of $75^{\circ} \mathrm{C}$, and a $1 \mathrm{M} \mathrm{NaCl}$ concentration.

Keywords: water sustainability, water recycling, chitosan, electrospun nanofibers, nickel adsorption, experimental design.
\end{abstract}

\section{Introduction}

Fresh water contamination with large range of pollutants, particularly, heavy metals, has become a major concern over last decades. Heavy metals, such as copper and nickel, released mainly from industrial activities, are considered to be highly harmful pollutants, even at low concentrations $[1,2]$. Due to their high toxicity and detrimental effects on the environment and human health, these contaminants must be removed from wastewater to meet stricter environmental legislations. During the last few years, new regulations have been established in many countries, regarding the discharge of toxic products into the environment. For example, an international standard was recently adopted by the World Health 
Organization (WHO) and Euro Environmental Contracts (EEC) limiting nickel discharge into surface waters to $0.02 \mathrm{mg} / \mathrm{L}[3,4]$.

Adsorption onto activated carbon is widely used for heavy metal removal from wastewater. However, activated carbon is an expensive material which restricts its use especially in developing countries $[5,6]$. Therefore, there is a growing need to find cheap and effective alternative adsorbents as a replacement for activated carbon. Those adsorbents will help to reduce operating costs, and improve competitiveness. In recent years, the search for low-cost adsorbents that have metal-binding capacities has intensified. Among them, agricultural wastes, fly ash, and natural zeolites are particularly of interest due to their adsorption characteristics and their availability (Babel and Kurniawan [7]). Numerous approaches have also been studied for the development of adsorbents containing natural polymers as reviewed by Crini [8]. Among them, polysaccharides, such as chitosan, represent an interesting and attractive alternative due to its specific structure, physico-chemical characteristics, chemical stability, high reactivity and excellent selectivity towards metals, resulting from the presence of amino functions in polymer chains. Chitosan is receiving considerable interest for heavy metals removal due to its excellent metal-binding capacities. Chitosan is a partial deacetylation derivative of the chitin polymer. It is also an abundant, natural, nontoxic, biodegradable and biocompatible polymer. It is well known to be a good natural adsorbent for metal ions due to important properties including a large number of hydroxyl groups which confers, a large number of primary amino groups used as adsorption sites, and a flexible polymer chain which provides suitable configuration for complexation of metal ions [8,9]. Macromolecular superstructures of chitosan with different forms such as gels and hydrogels networks, polymeric resins, beads, membranes, fibers or composite materials can be prepared by physical and chemical modifications as mentioned by Crini [8]. Unfortunately, under these forms, chitosan did not have both sufficient large surface area and good filtration properties (namely small pressure drop) which affect its adsorption rate and limit its application in column adsorption process.

To remedy to this problem, many researches were oriented to use chitosan as a nanofibrous nonwoven membrane by electrospinning technique $[8,10,11]$. Electrospinning of polymeric solutions has been widely studied for the preparation of fibrous materials with very fine diameters ranging from submicron to several nanometers, in a high voltage electrostatic field. The nanofibrous media prepared by this technique presents unique properties such as high specific surface area and high porosity with fine pores. Those properties are specifically required for the design of an effective adsorbent media for application in wastewater treatment. Unfortunately, electrospinning of pure chitosan solution is difficult due to its poor solubility, high viscosity and low stability in aqueous solutions. Dissolving it under acidic conditions and mixing it with another polymer such as polyethylene oxide (PEO) or polyvinyl alcohol (PVA), allow easy preparation of suitable nonwoven fabric by electrospinning for adsorption of heavy metals [11-13]. In order to optimize nickel ions adsorption capacity of chitosan blends electrospun nanofibers, many studies were carried out to investigate the effect of different parameters, such as, contact time, temperature, adsorbent amount, adsorbate 
concentration, added $\mathrm{NaCl}$ in the solution, etc. on the adsorption efficiency [12, 14]. However, few studies used systematically statistical methods such as response surface methodology (RSM) to determine individual and interactive effects of various physicochemical parameters on adsorption of contaminants with electrospun nanofibers. RSM is a very useful tool in optimization process, and is widely used in chemical engineering, and especially in adsorption studies (Pillai et al. [4]).

In this study, chitosan-polyethylene oxide nanofibers were first obtained using electrospinning method and characterized using scanning electron microscopy. Then, kinetic study was performed to evaluate their adsorption efficiency toward nickel ions and the effect of contact time. An investigation was then carried out to optimize $\mathrm{Ni}$ (II) adsorption capacity and to study the relationship between adsorption and selected physicochemical factors by RSM using a central composite face-centered experimental design (CCFD).

\section{Experimental}

\subsection{Materials}

Chitosan (75-85\% deacetylated) was used as the adsorbent material in this study. A highly concentrated acetic acid $\left(\mathrm{CH}_{3} \mathrm{COOH}\right)(80-90 \%)$, diluted to $50 \%$, was used to dissolve chitosan polymer to prepare chitosan solutions. Polyethylene oxide (PEO) powder (Mv 900,000) was used as an electrospinning co-agent. Nickel (II) sulfate hexahydrate $\left(\mathrm{NiSO}_{4} \cdot 6 \mathrm{H}_{2} \mathrm{O}\right)$ (ACS reagent, 99\%), was used as the main contaminant (adsorbate) in this study. All nickel solutions were prepared with distilled water. Chitosan, acetic acid, polyethylene oxide, and nickel (II) sulfate hexahydrate were supplied by Sigma-Aldrich (USA) and used without further purification. Sodium carbonate $\left(\mathrm{Na}_{2} \mathrm{CO}_{3}, 99+\%\right.$ ACS) was purchased from OMEGA chemical company (USA) and was used for neutralization treatment of chitosan/PEO nanofibrous nonwoven membranes. Ethylene diaminetetraacetic acid (EDTA) was purchased from OMEGA chemical company (USA) and used to determine residual $\mathrm{Ni}(\mathrm{II})$ in solution after adsorption trials using a titration method.

\subsection{Preparation of Cs/PEO solutions}

4\% chitosan and PEO solutions were prepared separately, in 50\% acetic acid and distilled water, respectively. The two solutions were stirred at ambient conditions for 18 to 24 hours, until complete dissolution of solutes. Then, a Cs/PEO 50:50 mass ratio blend solution was prepared and stirred at room temperature for 18 to 24 hours.

\subsection{Electrospinning of nanofiber membranes}

A horizontal electrospinning setup was used to make Cs/PEO nanofibers. The set up consists of a programmable micro-syringe pump (KD Scientific, model 100), equipped with a $5 \mathrm{ml}$ plastic syringe fitted with a 20 gauge stainless steel, blunt 
needle, a variable high DC voltage power supply (Gamma High Voltage Research, USA), a rotating cylindrical collector coated with aluminum foil (as a target for nanofibers). Based on the literature and laboratory tests, electrospinning experimental conditions were fixed as follows:

- Solution flow rate: $0.4 \mathrm{~mL} / \mathrm{hour}$

- Voltage: $25 \mathrm{kV}$

- $\quad$ Syringe diameter: $11.99 \mathrm{~mm}$

- Nozzle-Collector distance: $10 \mathrm{~cm}$

- Rotational speed of collector: $1500 \mathrm{rpm}$

- Temperature: $25^{\circ} \mathrm{C}$

\subsection{Neutralization treatment and nanofibers stability}

At the end of the electrospinning process, the nonwoven mats of $\mathrm{Cs} / \mathrm{PEO}$ nanofibers deposited on the aluminum foil were removed and dried in a vacuum chamber at $70^{\circ} \mathrm{C}$ for 24 hours in order to remove residual solvent. The mats were then neutralized by immersion in a $0.1 \mathrm{M}$ sodium carbonate $\left(\mathrm{Na}_{2} \mathrm{CO}_{3}\right)$ solution for 3 hours at ambient temperature. Then, the membranes were repeatedly washed with distilled water until a neutral $\mathrm{pH}$ was obtained, and dried at ambient temperature for 24 hours. To complete the process, a drying stage in an oven at $40^{\circ} \mathrm{C}$ was carried out overnight. This method was based on a study carried out by Sangsanoh and Supaphol [15].

\subsection{Nanofibers characterization}

In order to characterize the morphology of chitosan nanofiber mats, a JEOL-JSM 5500 scanning electron microscope (SEM) was used. The average nanofiber diameter, was determined using an image processing program (Image J), developed by the National Institutes of Health.

\subsection{Adsorption experiments}

$\mathrm{Cs} / \mathrm{PEO}$ electrospun nanofibers adsorption capacity toward nickel ions, were evaluated by performing an adsorption kinetic study. Adsorption batch experiments were carried out by soaking $25 \mathrm{mg}$ of adsorbent dose, in flasks containing $50 \mathrm{~mL}$ of a $100 \mathrm{ppm}$ nickel ions concentration solution. Flasks were then shaken using an orbital shaker (Lab line Instrument) at $200 \mathrm{rpm}$, at room temperature and $\mathrm{pH}$ 5.5. Effect of adsorbate-adsorbent time contact, on the adsorption capacity of nickel ions was then investigated. Residual nickel concentration was determined by titration using ethylenediaminetetraacetic acid (EDTA) according to a standard method developed by Bermejo-Barrera et al. [16]. The amount of nickel adsorbed, $\mathrm{q}(\mathrm{mg} / \mathrm{g})$ was calculated using the following equation:

$$
q=\left(C_{0}-C_{e q}\right) \frac{V}{m}
$$


where:

$C_{0}$ : Initial concentration of the nickel in solution $(\mathrm{mg} / \mathrm{L})$

$C_{e q}$ : Equilibrium concentration of nickel in solution $(\mathrm{mg} / \mathrm{L})$

$V$ : $\quad$ Solution volume (L)

$m$ : Mass of nanofibers (mg)

\subsection{Experimental design}

A 4 factors-3 levels central composite face-centered design (CCFD) was used to optimize the adsorption capacity of nickel ions on Cs/PEO electrospun nanofibers which is considered as the desired response of the design experiments. The four independent parameters were: Adsorbent dose, initial concentration of nickel ions, temperature, and $\mathrm{NaCl}$ concentration. $\mathrm{NaCl}$ was added in order to change solution conductivity. Table 1 presents the levels and ranges of independent parameters.

Table 1: Experimental range and levels of independent variables.

\begin{tabular}{|l|c|c|c|}
\hline \multirow{2}{*}{ Factors } & \multicolumn{3}{|c|}{ Range and coded levels } \\
\cline { 2 - 4 } & -1 & 0 & 1 \\
\hline Adsorbent dose $(\mathrm{mg})$ & 25 & 50 & 75 \\
\hline Initial nickel concentration $(\mathrm{mg} / \mathrm{L})$ & 100 & 200 & 300 \\
\hline Temperature $\left({ }^{\circ} \mathrm{C}\right)$ & 25 & 50 & 75 \\
\hline NaCl concentration $(\mathrm{M})$ & 0.1 & 0.5 & 1 \\
$($ Solution conductivity $(\mathrm{mS} / \mathrm{cm}))$ & $(17.6)$ & $(76)$ & $(138.5)$ \\
\hline
\end{tabular}

A sequence of 27 experiments was suggested by the statistical software and was conducted to obtain the desired response. Experiments were based on $\mathrm{CCF}$ design with sixteen factorial points, eight axial points (situated on the face of the cube), and three center points. Three replicates of the center point were carried out for estimating the pure error of the model. All experiments were randomized in order to reduce the effect of uncontrolled factors. A second order polynomial equation model was used for predicting and optimizing the desired response depending on different chosen factors, and expressed generally as follows:

$$
Y=C_{0}+\sum_{i=1}^{n} C_{i} X_{i}+\sum_{i=1}^{n} C_{i i} X_{i}^{2}+\sum_{i=1}^{n-1} n \sum_{j=i+1}^{n} C_{i j} X_{i} X_{j}
$$

where $\mathrm{Y}=$ the predicted response; $\mathrm{X}_{\mathrm{i}}, \mathrm{X}_{\mathrm{j}}=$ normalized values from -1 to +1 for a given independent variable, $C_{i}, C_{i i}=$ the ith variable coefficients, $C_{i j}=$ the $i j$ th interaction coefficients. A statistical software (JMP from SAS institute) was used for regression statistical analysis (Fisher-test and student test) and graphical analysis of data. The quality of fit of polynomial model equation was expressed by the regression coefficient $\left(\mathrm{R}^{2}\right)$ and adjusted $\mathrm{R}^{2}$. Response surface analysis was also used to better visualize the relationship between the desired response and every levels of each factors, as well as, optimum operating conditions and optimal response $[17,18]$. 


\section{Results and discussion}

\subsection{Morphology characterization of Cs/PEO nanofibers}

Figure 1 shows SEM images of 50:50 Cs/PEO electrospun nanofibers at two different magnifications, obtained after the electrospinning process. It can be seen that uniform, continuous and beadles nanofibers (nanometric scale), were obtained by electrospinning process at fixed experimental conditions. Average fibers diameter was found to be $\mathrm{D}=106 \mathrm{~nm}( \pm 12)$.
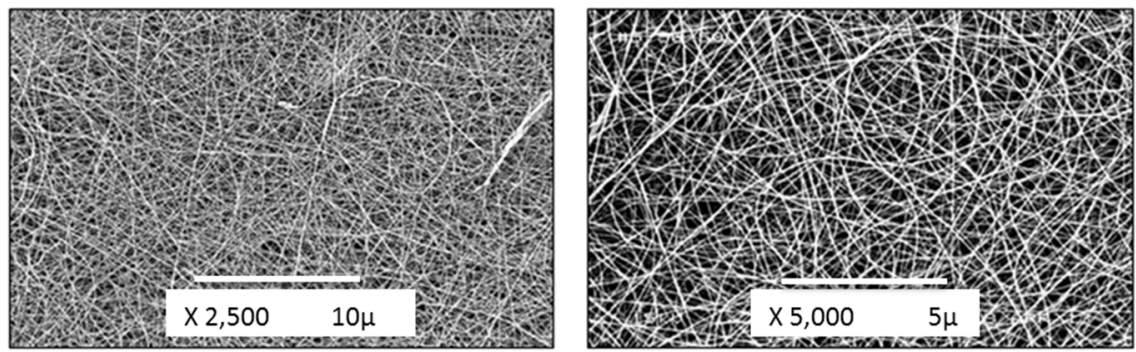

Figure 1: $\quad$ SEM images of Cs/PEO (50:50) electrospun nanofibers at different magnifications.

\subsection{Effect of contact time on $\mathrm{Ni}$ (II) adsorption capacity of $\mathrm{Cs} / \mathrm{PEO}$ nanofibers}

Figure 2 shows the effect of adsorbent-adsorbate contact time on Ni(II) adsorption capacity of $\mathrm{Cs} / \mathrm{PEO}$ nanofibers. As it can be noticed, the rate of $\mathrm{Ni}$ (II) removal is fast during the first 30 minutes, followed by a gradual decrease of the adsorption rate until equilibrium is achieved after 3.5 hours. At that moment, a maximum adsorption efficiency of about $30 \%$ is reached by using only $25 \mathrm{mg}$ of Cs/PEO nanofibers. This could be explained as follows: during the rapid phase of adsorption, almost all $\mathrm{Cs} / \mathrm{PEO}$ active sites become saturated with $\mathrm{Ni}(\mathrm{II})$. Thereafter, adsorbate molecules must go further and deeper through micro and nanopores of adsorbent, confronting, thus, much greater resistance, which slow down the adsorption rate $[19,20]$. At the end of this phase, membrane saturation is reached, and no significant enhancement in adsorption is observed. Thus, 3.5 hours is considered as optimum time for reaching the maximum $\mathrm{Ni}$ (II) adsorption, and it was selected for further experiments.

\subsection{Analysis of experimental design}

Randomized batch runs, based on the CCF design, were performed. The significant individual and quadratic factors effects, as well as their significant interactions, on the desired response were sorted and analyzed by performing a stepwise regression (Sall et al. [21]). 


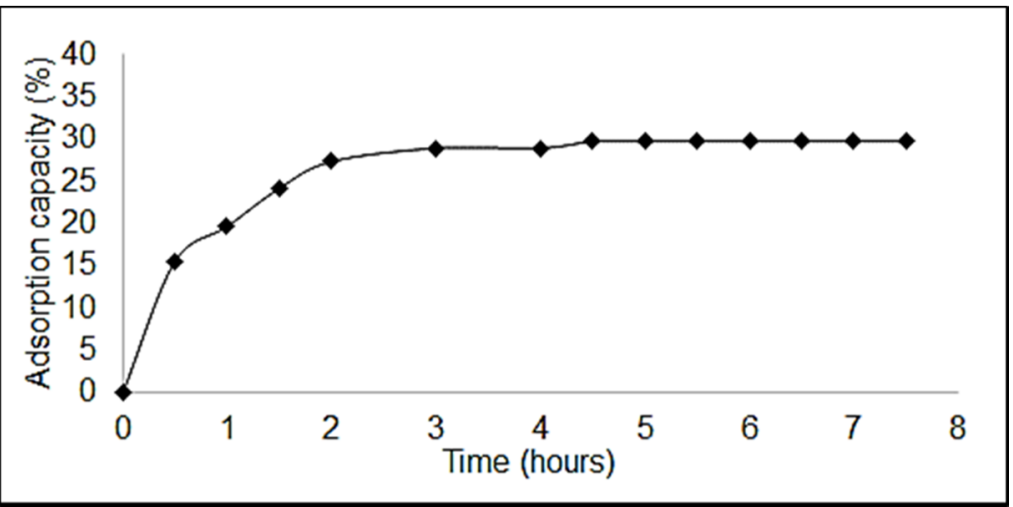

Figure 2: Adsorption kinetic of $\mathrm{Ni}(\mathrm{II})$ ions on 50:50 $\mathrm{Cs} / \mathrm{PEO}$ electrospun nanofibers. (Adsorbent dose $=25 \mathrm{mg}$, nickel initial concentration $=$ $100 \mathrm{ppm}, \mathrm{pH}=5.5$, temperature $=25^{\circ} \mathrm{C}$, no salt added in solution, agitation speed $=200 \mathrm{rpm})$.

\subsubsection{Regression analysis}

A quadratic model was obtained from observed data and a regression empirical equation, establishing the contribution of various significant factors on the desired response, is expressed as follows:

$$
\begin{aligned}
& Y=24.86+15.02 * N F-8.9 * C_{0}+1.54 * T+1.62 * N a C l \\
& -2.11 * N F^{2}+6.97 * C_{0}^{2}-4.51 * N F^{*} C_{0}+1.97 * N F * T-1.09 * C_{0} * T
\end{aligned}
$$

In order to estimate the quality of fit of the model, correlation coefficient $\left(\mathrm{R}^{2}\right)$, adjusted $\left(R^{2}\right)$, and the root mean square error (RMSE), were evaluated. A summary of fit analysis is presented in Table $2 . \mathrm{R}^{2}$ and $\mathrm{R}^{2}$ adjusted are found to be very high $\left(\mathrm{R}^{2}=0.9918, \mathrm{R}_{\mathrm{adj}}=0.9874\right)$ with a low estimated value of error standard deviation $(\mathrm{RMSE}=1.648)$, which is considered relatively small as compared to the scale of

Table 2: Summary of fit for the experimental design.

\begin{tabular}{|l|c|}
\hline \multicolumn{2}{|c|}{ Summary of fit } \\
\hline $\mathrm{R}^{2}$ & 0.9918 \\
\hline $\mathrm{R}^{2}$ adjusted & 0.9874 \\
\hline Root mean square error & 1.7346 \\
\hline Mean of response & 28.1074 \\
\hline Observations (or Sum Wgts) & 27 \\
\hline
\end{tabular}

the response, which confirm the high correlation degree between actual and predicted values. In other words, $99.18 \%$ of the sums of squares were captured by the model. These observations, can be confirmed by the plot of the predicted versus actual values presented in Figure 3 where all data values tend to follow a 
straight line with no extreme values (isolated points). This confirms the good agreement between response surface model and the actual values. Results of analysis of variance (ANOVA) illustrated in Table 3 show an F-value of 228.5277 for the model, with a low probability value $($ Prob $>$ F $)<0.05$, which implies that the model, as a whole, is considered as significant.

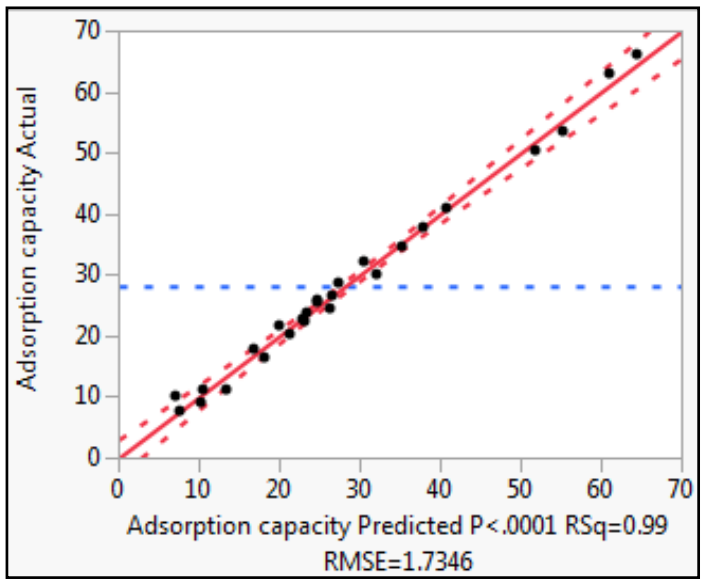

Figure 3: Plot of predicted versus actual values for Ni(II) adsorption.

Table 3: ANOVA analysis for the experimental design.

\begin{tabular}{|l|c|c|c|c|}
\hline \multicolumn{5}{|c|}{ ANOVA analysis } \\
\hline Source & DF & $\begin{array}{c}\text { Sum of } \\
\text { Squares }\end{array}$ & Mean Square & F Ratio \\
\hline Model & 9 & 6188.7722 & 687.641 & 228.5277 \\
\hline Error & 17 & 51.1531 & 3.009 & Prob $>$ F \\
\hline C. Total & 26 & 6239.9253 & & $<.0001^{*}$ \\
\hline
\end{tabular}

The parameter estimates (see Table 4) illustrates all significant effects at the 0.05 level, its standard errors, t-ratios and p-values. Results show that parameter estimates are in a good agreement with prediction equation given by eqn. (3). In fact, a positive value of the constant regression coefficients indicates a synergistic effect, where, the desired response, i.e. Ni(II) adsorption capacity increases in proportion manner with increasing the parameter. However, a negative value of the constants indicates an antagonistic effect, where desired response is inversely proportion to studied factor.

\subsubsection{Prediction profiler}

The relationship between desired response and individual factors can be given, as well, by surface profiler analysis illustrated in Figure 4. 
Table 4: Parameters estimates analysis given by regression analysis.

\begin{tabular}{|l|c|c|c|c|}
\hline \multicolumn{1}{|c|}{ Term } & Estimate & $\begin{array}{c}\text { Standard } \\
\text { error }\end{array}$ & t Ratio & Prob $>(\mathrm{t})$ \\
\hline Intercept & 24.862519 & 0.615558 & 40.39 & $<0.0001^{*}$ \\
\hline Adsorbent dose $(\mathrm{NF})$ & 15.028333 & 0.408861 & 36.76 & $<0.0001^{*}$ \\
\hline $\begin{array}{l}\text { Nickel initial concentration } \\
\left(\mathrm{C}_{0}\right)\end{array}$ & -8.903889 & 0.408861 & -21.78 & $<0.0001^{*}$ \\
\hline Temperature $(\mathrm{T})$ & 1.5355556 & 0.408861 & 3.76 & $0.0016^{*}$ \\
\hline $\mathrm{NaCl}$ concentration $(\mathrm{NaCl})$ & 1.615 & 0.408861 & 3.95 & $0.0010^{*}$ \\
\hline $\mathrm{NF} \mathrm{C}_{0}$ & -4.506875 & 0.433662 & -10.39 & $<0.0001^{*}$ \\
\hline $\mathrm{NF}{ }^{*} \mathrm{~T}$ & 1.973125 & 0.433662 & 4.55 & $0.0003^{*}$ \\
\hline $\mathrm{C}_{0} * \mathrm{~T}$ & -1.085625 & 0.433662 & -2.50 & $0.0228^{*}$ \\
\hline $\mathrm{NF}^{*} \mathrm{NF}$ & -2.106333 & 0.950106 & -2.22 & $0.0405^{*}$ \\
\hline $\mathrm{C}_{0} * \mathrm{C}_{0}$ & 6.9736667 & 0.950106 & 7.34 & $<0.0001^{*}$ \\
\hline
\end{tabular}

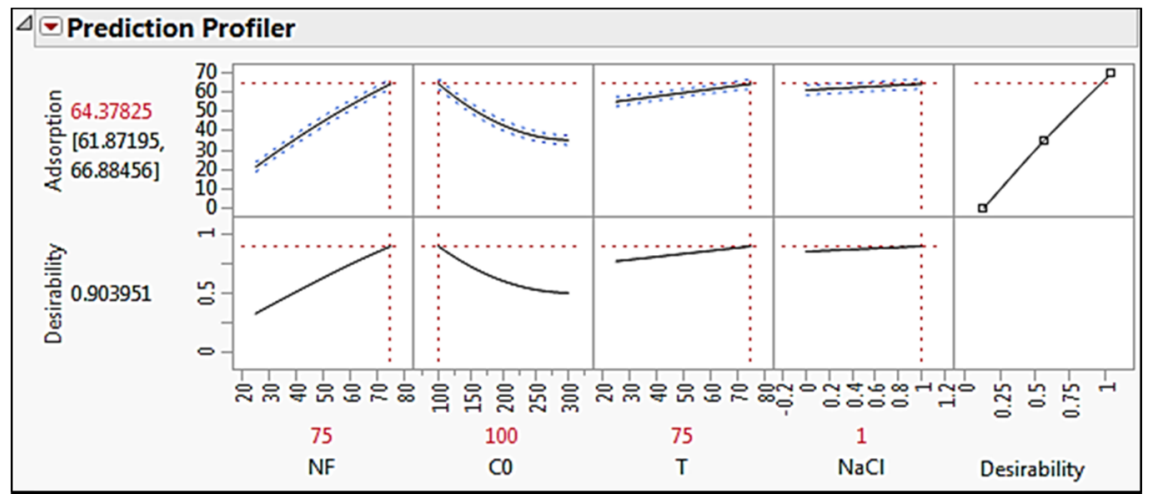

Figure 4: Surface profiler analysis: variation of desired response in function of investigated parameters and optimal solution.

It can be observed that adsorption capacity of nickel ions increases significantly with increasing adsorbent dose (NF), and slightly with increasing temperature (T) and salt concentration $(\mathrm{NaCl})$. However, it decreases dramatically with increasing $\mathrm{Ni}(\mathrm{II})$ initial concentration $\left(\mathrm{C}_{0}\right)$. Surface profiler analysis provides also, optimized conditions for an optimum desired response. As it is illustrated in Figure 4, an optimum adsorption capacity of nickel ions of about $64.4 \%$ can be obtained by using $75 \mathrm{mg}$ of adsorbent dose, in $\mathrm{Ni}$ (II) initial concentration of $100 \mathrm{ppm}$, at $75^{\circ} \mathrm{C}$, with adding $1 \mathrm{M}$ of $\mathrm{NaCl}$ in solution. Experiments were conducted in laboratory at these optimum conditions to compare predicted results of the model and experimental values. Results illustrated in Table 5 reveal a good agreement between experimental and predicted response values obtained at an optimum adsorption conditions at constant $\mathrm{pH}=5.5$ and contact time $=3.5$ hours. 
Table 5: Optimized process variables values.

\begin{tabular}{|c|c|c|c|c|c|c|c|}
\hline $\mathrm{pH}$ & $\begin{array}{c}\mathrm{t} \\
\text { (hours) }\end{array}$ & $\begin{array}{c}\mathrm{NF} \\
(\mathrm{mg})\end{array}$ & $\begin{array}{c}\mathrm{C}_{0} \\
(\mathrm{ppm})\end{array}$ & $\begin{array}{c}\mathrm{T} \\
\left({ }^{\circ} \mathrm{C}\right)\end{array}$ & $\begin{array}{c}\mathrm{NaCl} \\
(\mathrm{M})\end{array}$ & \multicolumn{2}{|c|}{ Adsorption capacity (\%) } \\
\cline { 7 - 9 } & 3.5 & 75 & 100 & 75 & 1 & 64.4 & 66.06 \\
\hline 5.5 & &
\end{tabular}

\subsubsection{Interaction effects on desired response analysis}

A three-dimensional response surface contour plots (Figure 5) was used to study the interaction effect between different adsorption variables two by two on the desired response while remaining other factors at zero level. Figure 5(a), 5(b), 5(c), presents the combined effect of adsorbent dose and initial concentration of $\mathrm{Ni}(\mathrm{II})$, adsorbent dose and temperature, and initial concentration of $\mathrm{Ni}(\mathrm{II})$ and temperature, respectively.

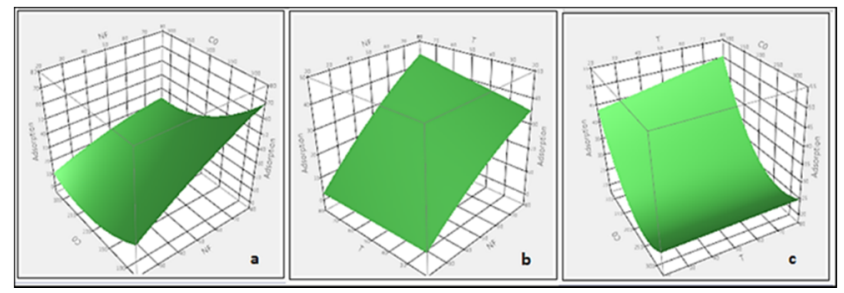

Figure 5: 3D Response surface. (a) Interactive effects of varied initial adsorbent dose and initial $\mathrm{Ni}(\mathrm{II})$ concentration at adsorption temperature $50^{\circ} \mathrm{C}$ and $\mathrm{NaCl}$ concentration of $0.5 \mathrm{M}$. (b) Interactive effects of varied initial adsorbent dose and temperature at initial $\mathrm{Ni}(\mathrm{II})$ concentration of $200 \mathrm{ppm}$ and $\mathrm{NaCl}$ concentration of $0.5 \mathrm{M}$. (c) Interactive effects of initial $\mathrm{Ni}(\mathrm{II})$ concentration and adsorption temperature at initial adsorbent dose of $50 \mathrm{mg}$ and $\mathrm{NaCl}$ concentration of $0.5 \mathrm{M}$.

Surface profiler results confirm previous regression analysis results. As it can be seen, adsorption capacity of 50:50 Cs/PEO electrospun nanofibers toward $\mathrm{Ni}(\mathrm{II})$ is significantly influenced by adsorbent dose and initial concentration of $\mathrm{Ni}(\mathrm{II})$ interaction, compared to other interaction effects (Figure 5(b) and Figure 5(a)). From Figure 5(a), it can be observed that a maximum adsorption value can be reached using a maximum of adsorbent dose at a minimum initial concentration of $\mathrm{Ni}(\mathrm{II})$, at a constant temperature $\left(50^{\circ} \mathrm{C}\right)$ and $\mathrm{NaCl}$ concentration $(0.5 \mathrm{M})$. Figure 5 (b) reveals that, at constant adsorbent dose $(50 \mathrm{mg})$, and initial concentration of $\mathrm{Ni}(\mathrm{II})(200 \mathrm{ppm})$, a maximum response is obtained with maximum temperature and $\mathrm{NaCl}$ concentration values. Figure 5(c) shows that a maximum desirability is attained at high temperature values and low initial concentration of $\mathrm{Ni}(\mathrm{II})$ values, while maintaining other variables at zero levels.

\section{Conclusions}

Continuous, uniform and beadles $\mathrm{Cs} / \mathrm{PEO}$ nanofibers (50:50 mass ratio) were successfully obtained using electrospinning process. Kinetics study revealed the 
adsorption efficiency of electrospun nanofibers toward nickel ions and equilibrium time to reach membrane saturation was found to be 3.5 hours. RSM was used to optimize adsorption process conditions, by adopting a composite face centered experimental design (CCF). RSM results suggest that desired response (i.e. nickel adsorption capacity of $\mathrm{Cs} / \mathrm{PEO}$ nanofibers) is proportionally increased with increasing the adsorbent dose, temperature, and $\mathrm{NaCl}$ concentration, and with decreasing Ni(II) initial concentration. The interaction effect between different variables on desired response was observed as well. Results revealed that response was considerably significant for adsorbent dose and $\mathrm{Ni}(\mathrm{II})$ initial concentration interaction, compared to other interactions $\left(\mathrm{NF}^{*} \mathrm{~T}\right.$ and $\left.\mathrm{C}_{0} * \mathrm{~T}\right)$ which was considered moderately significant. Optimum Ni(II) uptake capacity of $64 \%$ was obtained at the following optimum operating conditions: $\mathrm{pH}=5.5$; contact time $=$ 3.5 hours, adsorbent dose $=75 \mathrm{mg}$, Ni(II) initial concentration $=100 \mathrm{ppm}$; temperature $=75^{\circ} \mathrm{C}, \mathrm{NaCl}$ concentration $=1 \mathrm{M}$.

\section{Acknowledgements}

The authors gratefully acknowledge the financial support of the Natural Science and Engineering Research Council of Canada (NSERC). Authors also thank CRMR and CQMF, two strategic clusters supported by the Government of Quebec.

\section{References}

[1] Dirilgen, N., Accumulation of heavy metals in freshwater organisms: Assessment of toxic interactions. Turkish Journal of Chemistry, 25(2), pp. 173-179, 2001.

[2] Nagajyoti, P., Lee, K. \& Sreekanth, T., Heavy metals, occurrence and toxicity for plants: a review. Environmental Chemistry Letters, 8(3), pp. 199-216, 2010.

[3] Krewski, D., Balbus, J., Butler-Jones, D., Haas, C., Isaac-Renton, J., Roberts, K.J. \& Sinclair, M., Managing health risks from drinking water a report to the Walkerton inquiry. Journal of Toxicology and Environmental Health Part A, 65(21), pp. 1635-1823, 2002.

[4] Pillai, M.G., Regupathi, I., Kalavathy, M.H., Murugesan, T. \& Miranda, L.R., Optimization and analysis of nickel adsorption on microwave irradiated rice husk using response surface methodology (RSM). Journal of Chemical Technology and Biotechnology, 84(2), pp. 291-301, 2009.

[5] Jiuhui, Q., Research progress of novel adsorption processes in water purification: A review. Journal of Environmental Sciences, 20(1), pp. 1-13, 2008.

[6] Sharma, D. \& Forster, C., Removal of hexavalent chromium from aqueous solutions by granular activated carbon. Water $S$. A., 22(2), pp. 153-160, 1996. 
[7] Babel, S. \& Kurniawan, T.A., Low-cost adsorbents for heavy metals uptake from contaminated water: a review. Journal of hazardous materials, 97(1), pp. 219-243, 2003.

[8] Crini, G., Recent developments in polysaccharide-based materials used as adsorbents in wastewater treatment. Progress in polymer science, 30(1), pp. 38-70, 2005.

[9] Vold, I.M., Vårum, K.M., Guibal, E. \& Smidsrød, O., Binding of ions to chitosan-selectivity studies. Carbohydrate Polymers, 54(4), pp. 471-477, 2003.

[10] Harris, D.K., Cahela, D.R. \& Tatarchuk, B.J., Wet layup and sintering of metal-containing microfibrous composites for chemical processing opportunities. Composites Part A: applied science and manufacturing, 32(8), pp. 1117-1126, 2001.

[11] Homayoni, H., Ravandi, S.A.H. \& Valizadeh, M., Electrospinning of chitosan nanofibers: Processing optimization. Carbohydrate Polymers, 77(3), pp. 656-661, 2009.

[12] Esmaeili, A. \& Beni, A.A., A novel fixed-bed reactor design incorporating an electrospun PVA/chitosan nanofiber membrane. Journal of hazardous materials, 280, pp. 788-796, 2014.

[13] Teo, W. \& Ramakrishna, S., A review on electrospinning design and nanofibre assemblies. Nanotechnology, 17(14), pp. R89, 2006.

[14] Heidari, A., Younesi, H., Mehraban, Z. \& Heikkinen, H., Selective adsorption of $\mathrm{Pb}$ (II), $\mathrm{Cd}$ (II), and $\mathrm{Ni}$ (II) ions from aqueous solution using chitosan-MAA nanoparticles. International journal of biological macromolecules, 61, pp. 251-263, 2013.

[15] Sangsanoh, P. \& Supaphol, P., Stability improvement of electrospun chitosan nanofibrous membranes in neutral or weak basic aqueous solutions. Biomacromolecules, 7(10), pp. 2710-2714, 2006.

[16] Bermejo-Barrera, A., Bermejo-Barrera, P. \& Bermejo Martinez, F., Simultaneous determination of copper and cobalt with EDTA using derivative spectrophotometry. Analyst, 110(11), pp. 1313-1315, 1985.

[17] Montgomery, D.C., Design and analysis of experiments 5th edition, John Wiley and Sons: New York, p. 696, 2001.

[18] Myers, R.H., Montgomery, D.C. \& Anderson-Cook, C.M., Response surface methodology: process and product optimization using designed experiments, John Wiley and Sons, p. 704, 2009.

[19] Srivastava, V.C., Mall, I.D. \& Mishra, I.M., Adsorption of toxic metal ions onto activated carbon: Study of sorption behaviour through characterization and kinetics. Chemical Engineering and Processing: Process Intensification, 47(8), pp. 1269-1280, 2008.

[20] Zogorski, J.S., Faust, S.D. \& Haas, J.H., The kinetics of adsorption of phenols by granular activated carbon. Journal of Colloid and Interface Science, 55(2), pp. 329-341, 1976.

[21] Sall, J., Lehman, A., Stephens, M.L. \& Creighton, L., JMP start statistics: a guide to statistics and data analysis using JMP, SAS Institute: 2012. 